\title{
PROBABILISTIC BEHAVIOUR OF JOINTS ON JOINT FORCES IN MECHANISMS
}

\author{
Boštjan Harl, Nenad Gubeljak, Marko Kegl
}

Original scientific paper

This paper discusses the influence of the clearance in joints on the joint reaction forces in mechanisms. By using mathematical programming, the optimal parameters of kinematic chains can be efficiently obtained by using the deterministic approach. However, the situation becomes more sophisticated if random effects of tolerances of the arm lengths and the random pin positions have to be considered. In this work the influence of clearances on joint forces is calculated by using the Taylor approximation and the Monte Carlo method. The implementation of the model is illustrated with two examples. The first example considers a closed loop chain, representing a four-bar mechanism being an actual part of a hydraulic support, employed in mining industry. The second example considers joint reaction forces of car wiper mechanism.

Keywords: joint forces; kinematic chain; mathematical programming; stochastic model

\section{Probabilističko ponašanje spojeva na spojnim silama mehanizama}

Izvorni znanstveni članak

U radu se razmatra utjecaj zračnosti u spojevima na reakcijske sile spoja u mehanizmima. Pomoću matematičkog programiranja, uspješno se mogu dobiti optimalni parametri kinematičkih lanaca primjenom determinističkog pristupa. Međutim, situacija postaje složenija ako se moraju uzeti u obzir slučajni učinci tolerancije dužine poluge (kraka) i slučajni položaji svornjaka. U ovom se radu utjecaj zračnosti na spojne sile izračunao pomoću Taylor aproksimacije i Monte Carlo metode. Implementacija modela ilustrirana je na dva primjera. Prvi primjer razmatra lanac zatvorene petlje, predstavljajući mehanizam s četiri šipke kao sastavnog dijela hidrauličkog nosača, korištenog u rudarstvu. Drugi primjer razmatra reaktivne sile spoja u mehanizmu automobilskog brisača.

Ključne riječi: kinematički lanac; matematičko programiranje; spojne sile; stohastički model

\section{Introduction}

Kinematic chains are widely used in industry [1], which is also reflected in extensive literature and studies available, see e.g. [2, 3, 4]. For the analysis and synthesis of kinematic chains, optimization methods have proved to be a valuable tool. Consequently, since the 1960s, various formulations for optimization of problems related to kinematic chains have been developed, see e.g. [5]. Some good examples are the optimal track problem of a closed kinematic chain [6] and the problem related to the impact of tolerances of arm lengths and random pin positions, discussed in $[7,8]$.


Figure 1Hydraulic support engagement in a mine (a) and the schematic model of the hydraulic support (b)

The first example is a hydraulic support, Fig. 1a, that is a part of the mining industry equipment in the mine Velenje - Slovenia, used for protection of working environment in
In this paper, the study is conducted on two examples. The first one is the kinematic chain with the optimal length of the links, obtained in [6] by employing optimization methods, and the second example is a car wiper mechanism. For both examples the influence of the clearances in the joints on the joint reaction forces is studied. This is achieved by an adequate mathematical model that reflects the effects of tolerances of arm lengths and random pin positions. The influence of clearances on joint forces is calculated by the Taylor approximation and the Monte Carlo method. the gallery. It consists of two four-bar mechanisms FEDG and AEDB as shown on Fig. 1b. The mechanism AEDB defines the path of the coupler point $\mathrm{C}$ and the mechanism 
FEDG is used to drive the support by a hydraulic actuator. The original support design exhibited large transversal displacements of the point $\mathrm{C}$ and relatively very high joint forces, which reduced its employability. This was the reason to determine the best values for the most problematic parameters of leading four-bar mechanism
AEDB by employing the methods of mathematical programming $[9,10]$. In this work, the influence of the clearance in joints on the joint reaction forces will be studied for the four-bar mechanism AEDB of the support, Fig. 1b.

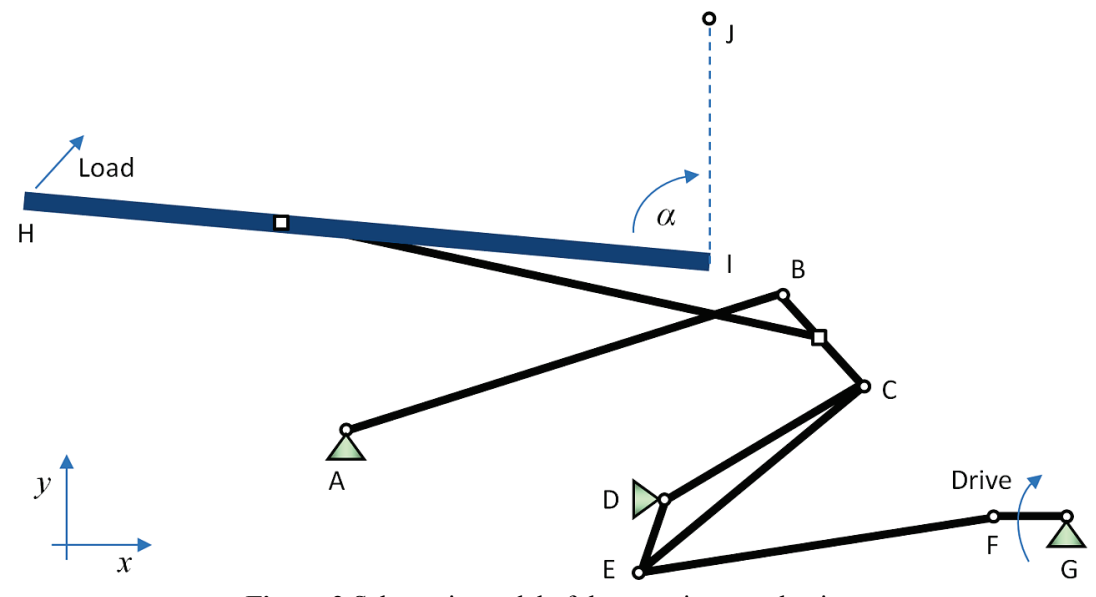

Figure 2 Schematic model of the car wiper mechanism

The car wiper mechanism consists of two four-bar mechanisms ADCB and DGFE as shown in Fig. 2.The clearance in joints on the joint reaction forces will be studied for the ADCB mechanism.

\section{The stochastic model of the mechanism}

The foundation of our considerations is an appropriate mechanical model of the mechanical system kinematic chain, which will enable the computation of the kinematic and dynamic quantities [11]. We assume here that this model is given by a system of $m$ response equations, written as

$h_{i}(\boldsymbol{b}, \boldsymbol{u})=0, \quad i=1,2, \cdots, m$

The response equations allow us to compute the vector of response variables $(\boldsymbol{u})$ in dependence on the vector of some design variables $(\boldsymbol{b})$. This implies that $\boldsymbol{u}=\widetilde{\boldsymbol{h}}(\boldsymbol{b})$, where $\tilde{\boldsymbol{h}}$ denotes a vector function establishing the relationship between the vector of design variables and the response of our mechanical system.

In a stochastic model, the vector $\boldsymbol{b}$ is treated as a random vector $\boldsymbol{B}=\left[B_{1}, B_{2}, \ldots, B_{n}\right]^{\mathrm{T}}$, meaning that the vector $\boldsymbol{u}$ of response variables is also a random vector $\boldsymbol{U}=\left[U_{1}, U_{2}, \ldots, U_{m}\right]^{\mathrm{T}}$, where is $\boldsymbol{U}=\tilde{\boldsymbol{h}}(\boldsymbol{B})$. It is supposed that the design variables $B_{1}, B_{2}, \ldots, B_{n}$ are mutually independent, at least from the probability point of view.

The probability distribution function of the random vector $\boldsymbol{U}$, that is searched for, depends on the probability distribution function of the random vector $\boldsymbol{B}$ and it is mostly practically impossible to compute. Therefore, the random vector $\boldsymbol{U}$ will be described either by the help of "number characteristics", that can be estimated by a Taylor approximation of the function $\tilde{\boldsymbol{h}}$ at the point $\boldsymbol{b}$, or by using the Monte Carlo method.

\subsection{Taylor approximation}

Let in some probability space be defined $n$ independent random variables. Since it is practically impossible to compute the probability distribution function of the random vector $\boldsymbol{U}$, where $\boldsymbol{U}=\tilde{\boldsymbol{h}}(\boldsymbol{B})$, the number characteristics $\mu_{U}$ and $\sigma_{U}$ can be estimated by the Taylor approximation of the function $\tilde{\boldsymbol{h}}$ at the point $\boldsymbol{b}=\left[b_{1}, b_{2}, \ldots, b_{n}\right]^{\mathrm{T}}$ as follows

$\widetilde{h}\left(B_{1}, B_{2}, \ldots B_{n}\right)=\widetilde{h}\left(b_{1}, b_{2}, \ldots b_{n}\right)+$

$+\sum_{i=1}^{n} \frac{\partial \tilde{h}\left(b_{1}, b_{2}, \ldots b_{n}\right)}{\partial b_{i}}\left(B_{i}-b_{i}\right)+$

$+\frac{1}{2}\left(\sum_{i=1}^{n} \frac{\partial^{2} \tilde{h}\left(b_{1}, b_{2}, \ldots b_{n}\right)}{\partial b_{i}^{2}}\left(B_{i}-b_{i}\right)^{2}+\right.$

$\left.+\sum_{i}^{n} \sum_{j}^{n} \frac{\partial^{2} \widetilde{h}\left(b_{1}, b_{2}, \ldots b_{n}\right)}{\partial b_{i} \partial b_{j}}\left(B_{i}-b_{i}\right)\left(B_{j}-b_{j}\right)\right)+R_{3}$.

For the examples under consideration, it is assumed that the remainder $\left|R_{3}\right|$ is small so that it can be neglected. The mathematical expectation $\mu_{U}$ for the random vector $\boldsymbol{U}$ can be formulated as

$\mu_{U}=\tilde{h}\left(b_{1}, b_{2}, \ldots b_{n}\right)+\frac{1}{2} \sum_{i=1}^{n} \frac{\partial^{2} \tilde{h}\left(b_{1}, b_{2}, \ldots b_{n}\right)}{\partial b_{i}^{2}} \sigma_{i}^{2}$

Since $\sigma_{i}<<b_{i}$ the second part of Eq. (3) can also be neglected. Therefore, the final expression for the mathematical expectation is 


$$
\mu_{U}=\tilde{h}\left(b_{1}, b_{2}, \ldots b_{n}\right)
$$

The standard deviation $\sigma_{U}$ can be written as

$$
\sigma_{U}^{2}=E\left(\left(U-\mu_{U}\right)^{2}\right)=E\left(U^{2}\right)-\mu_{U}^{2}
$$

Where

$$
\begin{aligned}
& E\left(U^{2}\right)=\left(\tilde{h}\left(b_{1}, b_{2}, \ldots b_{n}\right)\right)^{2}+\sum_{i=1}^{n}\left(\frac{\partial \tilde{h}\left(b_{1}, b_{2}, \ldots b_{n}\right)}{\partial b_{i}}\right)^{2} \sigma_{i}^{2}+ \\
& +\tilde{h}\left(b_{1}, b_{2}, \ldots b_{n}\right) \sum_{i=1}^{n}\left(\frac{\partial^{2} \tilde{h}\left(b_{1}, b_{2}, \ldots b_{n}\right)}{\partial b_{i}^{2}}\right) \sigma_{i}^{2}+ \\
& +\sum_{i=1}^{n}\left(\frac{\partial \tilde{h}\left(b_{1}, b_{2}, \ldots b_{n}\right)}{\partial b_{i}}\right)\left(\frac{\partial^{2} \tilde{h}\left(b_{1}, b_{2}, \ldots b_{n}\right)}{\partial b_{i}^{2}}\right) E\left(\left(B_{i}-b_{i}\right)^{3}\right) .
\end{aligned}
$$

By neglecting the small terms and combining Eqs. (5) and (6), one can derive the standard deviation of the independent variable $U$ in the following form

$$
\sigma_{U}=\sqrt{\left(\sum_{i=1}^{n}\left(\frac{\partial \tilde{h}\left(b_{1}, b_{2}, \ldots, b_{n}\right)}{\partial b_{i}}\right)^{2} \sigma_{i}^{2}\right)} .
$$

By assuming that the design variables $B_{1}, \cdots, B_{n}$ are mutually independent from the probability point of view and assuming that they exhibit normal distribution, the exact $\mu_{U}$ and $\sigma_{U}$ can be calculated as $B_{j} \sim N\left(\mu_{j}, \sigma_{j}\right)$ $(j=1,2, \cdots, n)$.

\subsection{Method Monte Carlo}

The Monte Carlo method can be employed as a robust approach to simulate the production process of a mechanical system by engaging its mathematical model. After that statistical methods can be used to obtain $\mu_{U}$ and $\sigma_{U}$. If the production process is defined as a "black box", the random generator can be utilized to get the random variables $B_{1}, B_{2}, \ldots B_{n}$ and further random $\boldsymbol{U}$ can be computed as $U=\tilde{h}\left(B_{1}, B_{2}, \ldots B_{n}\right)$. If this procedure is repeated $n$ times, the sample $U_{1}, U_{2}, \ldots U_{n}$ is obtained. The $\mu_{U}$ and $\sigma_{U}$ are then given by

$\mu_{U}=\frac{\sum_{i=1}^{n} U_{i}}{n}, \sigma_{U}=\frac{\sum_{i=1}^{n}\left(\mu_{U}-U_{i}\right)^{2}}{n-1}$.

\section{Clearance in joints}

In this work, the effective link length model is used [8]. This model considers the uncertainties due to pin location, link length tolerance, and radial clearance tolerance as an effective length variation of the link. Therefore, the local configuration of each pin joint does not affect the model. The effective link length model is shown in Fig. 3.

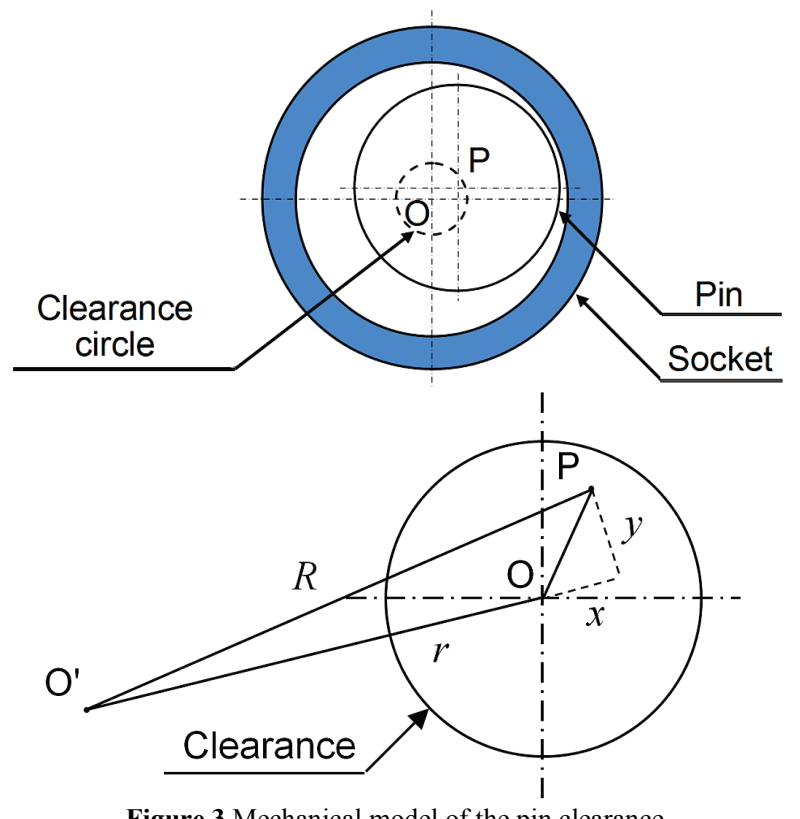

Figure 3 Mechanical model of the pin clearance

As the pin moves inside the inner circle of the socket, the pin centre moves on or inside the clearance circle. The radius of the clearance circle, i.e. the radial clearance, is determined by the tolerances of the pin and socket diameters. Since most tolerances follow a normal distribution at the worst case, the probability distribution of the pin position is assumed to follow such distributions in order to analyse the pin joint successfully. This model, the clearance model, readily accounts for uncertainties in a pin joint such as tolerance of the radial clearance and random location of the pin.

Let the length of the link $\overline{\mathrm{O}} \mathrm{O}$ be given by the quantity $r$, which already contains the tolerance associated with the length. The local coordinate frame for pin location $\mathrm{P}(x, y)$ is chosen in such a way that:

- the coordinate axis coincides with the centre line of the link,

- the coordinate origin is located at the socket centre,

- the right hand rule determines the axis $y$.

Hence, the origin of such a frame coincides with the socket centre $\mathrm{O}$ and the axis $x$ is parallel to the nominal link direction. The line $\overline{\mathrm{O}} \mathrm{P}$ represents the effective link and its length is given as

$R=\sqrt{(r+x)^{2}+y^{2}}$

Where $x$ and $y$ are the coordinates of the random pin location in the local coordinate frame and $r$ is random link length.

\section{$4 \quad$ Numerical examples}

Two numerical examples will be considered. The influence of the clearance in joints A, E, D, B of the hydraulic support (Fig. 1b) and for joints A, D, C, B of 
the car wiper (Fig. 2) on the joint reaction forces will be calculated.

The symbols $F_{j}$, where $j=1, \ldots, 4$, represent the norms of the joint force vector. By using the Taylor approximation, the influence for all four joints can be estimated by the standard deviations

$$
\begin{aligned}
& \sigma_{1}=\sqrt{\sum_{i=1}^{4}\left(\frac{\partial F_{1}}{\partial u_{i}}\right)^{2}\left(\frac{\Delta r_{i}}{6}\right)^{2}+\left(\frac{\partial F_{1}}{\partial x}\right)^{2}\left(\frac{\Delta x}{6}\right)^{2}+\left(\frac{\partial F_{1}}{\partial y}\right)^{2}\left(\frac{\Delta y}{6}\right)^{2}}, \\
& \sigma_{2}=\sqrt{\sum_{i=1}^{4}\left(\frac{\partial F_{2}}{\partial u_{i}}\right)^{2}\left(\frac{\Delta r_{i}}{6}\right)^{2}+\left(\frac{\partial F_{2}}{\partial x}\right)^{2}\left(\frac{\Delta x}{6}\right)^{2}+\left(\frac{\partial F_{2}}{\partial y}\right)^{2}\left(\frac{\Delta y}{6}\right)^{2}}, \\
& \sigma_{3}=\sqrt{\sum_{i=1}^{4}\left(\frac{\partial F_{3}}{\partial u_{i}}\right)^{2}\left(\frac{\Delta r_{i}}{6}\right)^{2}+\left(\frac{\partial F_{3}}{\partial x}\right)^{2}\left(\frac{\Delta x}{6}\right)^{2}+\left(\frac{\partial F_{3}}{\partial y}\right)^{2}\left(\frac{\Delta y}{6}\right)^{2}}, \\
& \sigma_{4}=\sqrt{\sum_{i=1}^{4}\left(\frac{\partial F_{4}}{\partial u_{i}}\right)^{2}\left(\frac{\Delta u_{i}}{6}\right)^{2}+\left(\frac{\partial F_{4}}{\partial x}\right)^{2}\left(\frac{\Delta x}{6}\right)^{2}+\left(\frac{\partial F_{4}}{\partial y}\right)^{2}\left(\frac{\Delta y}{6}\right)^{2}} .
\end{aligned}
$$

In the above equations, $\Delta r_{i}$ are the tolerances of the link lengths of AEDB and ADCB mechanisms, while $\Delta x$ and $\Delta y$ are the tolerances of the pin and the socket.

During numerical investigation, it turned out that the Taylor approximation usually yields satisfying results only for small values of $\Delta r_{i}, \Delta x$, and $\Delta y$. For this reason it makes sense to compute the required quantities also by another independent method. In our case the Monte Carlo method was engaged for this purpose. In this case the influence of clearances on joint forces can be computed as

$\mu_{1}=\frac{\sum_{i=1}^{n} F_{1_{i}}}{n}, \mu_{2}=\frac{\sum_{i=1}^{n} F_{2 i}}{n}, \mu_{3}=\frac{\sum_{i=1}^{n} F_{3 i}}{n}, \mu_{4}=\frac{\sum_{i=1}^{n} F_{4 i}}{n}$

$\sigma_{1}=\frac{\sum_{i=1}^{n}\left(\mu_{1}-F_{1 i}\right)^{2}}{n-1}, \sigma_{2}=\frac{\sum_{i=1}^{n}\left(\mu_{2}-F_{2 i}\right)^{2}}{n-1}$,

$\sigma_{3}=\frac{\sum_{i=1}^{n}\left(\mu_{3}-F_{3 i}\right)^{2}}{n-1}, \sigma_{4}=\frac{\sum_{i=1}^{n}\left(\mu_{4}-F_{4_{i}}\right)^{2}}{n-1}$.

\subsection{Hydraulic support}

The carrying capability of the hydraulic support is $1600 \mathrm{kN}$. Both four-bar mechanisms AEDB and FEDG must fulfil the following requirements:

- they must exhibit minimal transversal displacements of the point $\mathrm{C}$,

- $\quad$ they must provide sufficient side stability.

The starting parameters of both four-bar mechanisms (Fig. 1b) were the values obtained in the earlier work by optimization. These values are (in millimetres):

$[\overline{\mathrm{AE}}, \overline{\mathrm{AB}}, \overline{\mathrm{BD}}, \overline{\mathrm{DE}}]^{\mathrm{T}}=[676,1361,382,1310]^{\mathrm{T}}$,

and
$[\overline{\mathrm{EF}}, \overline{\mathrm{FG}}, \overline{\mathrm{GD}}, \overline{\mathrm{DE}}]^{\mathrm{T}}=[400,(1325+d), 1251,1310]^{\mathrm{T}}$.

The parameter $d$ is a displacement of the hydraulic actuator with a maximal value of $925 \mathrm{~mm}$. During operation, the parameter $d$ varies, so that the angle $\alpha$ between links $\overline{\mathrm{AB}}$ and $\overline{\mathrm{AE}}$ can be varied in the range from $76,8^{\circ}$ to $94,8^{\circ}$.

For the selected pin and socket, the maximal values of $x$ and $y$ in (9) are given in [11].These values are $x=y=2 \mathrm{~mm}$. For calculating the clearances, the tolerances of the links of the four-bar mechanism AEDB are needed and the values, in millimetres, are

$\left[\Delta r_{1}, \Delta r_{2}, \Delta r_{3}, \Delta r_{4}\right]^{\mathrm{T}}=[0,01971 ; 0,00868 ; 0,001 ; 0,00933]^{\mathrm{T}}$, meanwhile, the tolerances of the clearance are

$[\Delta x, \Delta y]^{\mathrm{T}}=[0,001 ; 0,001]^{\mathrm{T}}$

By using this data the deterministic joint forces in the hydraulic support, during the variation of $d$, can be computed. Their histories are shown in Figure 4, where: $F_{1}$ (full line - blue), $F_{2}$ (dotted line - green), $F_{3}$ (dashed line - yellow) and $F_{4}$ (dash-dotted line -red).

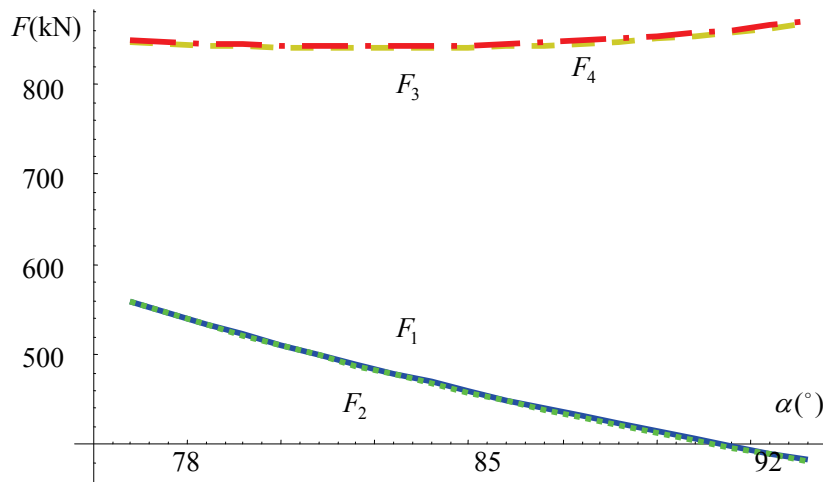

Figure 4 Joint forces of the mechanism AEDB

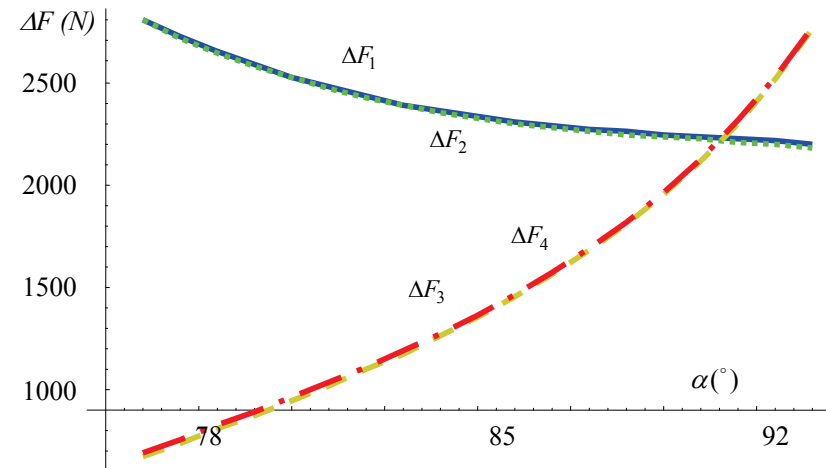

Figure 5 The effect of clearances on the joint forces of the mechanism AEDB obtained by the Taylor approximation

By using Eq. (10) it is now possible to estimate the effect of clearances on joint reaction forces, obtained by the Taylor approximation. The variations of these forces are shown in Fig. 5, where: $\Delta F_{1}$ (full line - blue), $\Delta F_{2}$ (dotted line - green), $\Delta F_{3}$ (dashed line - yellow) and $\Delta F_{4}$ (dashed-dotted -red). 


\subsection{Car wiper}

The car wiper, Fig. 2, is loaded by a force of $20 \mathrm{~N}$. The starting parameters, in millimetre, are

$[\overline{\mathrm{AB}}, \overline{\mathrm{BC}}, \overline{\mathrm{CD}}, \overline{\mathrm{AD}}]^{\mathrm{T}}=[200,40,100,125]^{\mathrm{T}}$,

and

$$
[\overline{\mathrm{DE}}, \overline{\mathrm{EF}}, \overline{\mathrm{FG}}, \overline{\mathrm{DG}}]^{\mathrm{T}}=[42,5 ; 110 ; 11,5 ; 220]^{\mathrm{T}} \text {. }
$$

The drive of the car wiper mechanism is defined as $f(t)$ and can vary the angle $\alpha$ between the links $\overline{\mathrm{IH}}$ and $\overline{\mathrm{IJ}}$ from $10^{\circ}$ to $90^{\circ}$. For the selected pin and socket, the maximal values of $x$ and $y$ are $x=y=0,2 \mathrm{~mm}$. To compute the clearances, the tolerances of the links of the four-bar mechanism ADCB are needed. Their values, in millimetres, are

$$
\left[\Delta r_{1}, \Delta r_{2}, \Delta r_{3}, \Delta r_{4}\right]^{\mathrm{T}}=[0,01 ; 0,01 ; 0,01 ; 0,01]^{\mathrm{T}}
$$

The tolerances of the clearance are

$$
[\Delta x, \Delta y]^{\mathrm{T}}=[0,001 ; 0,001]^{\mathrm{T}}
$$
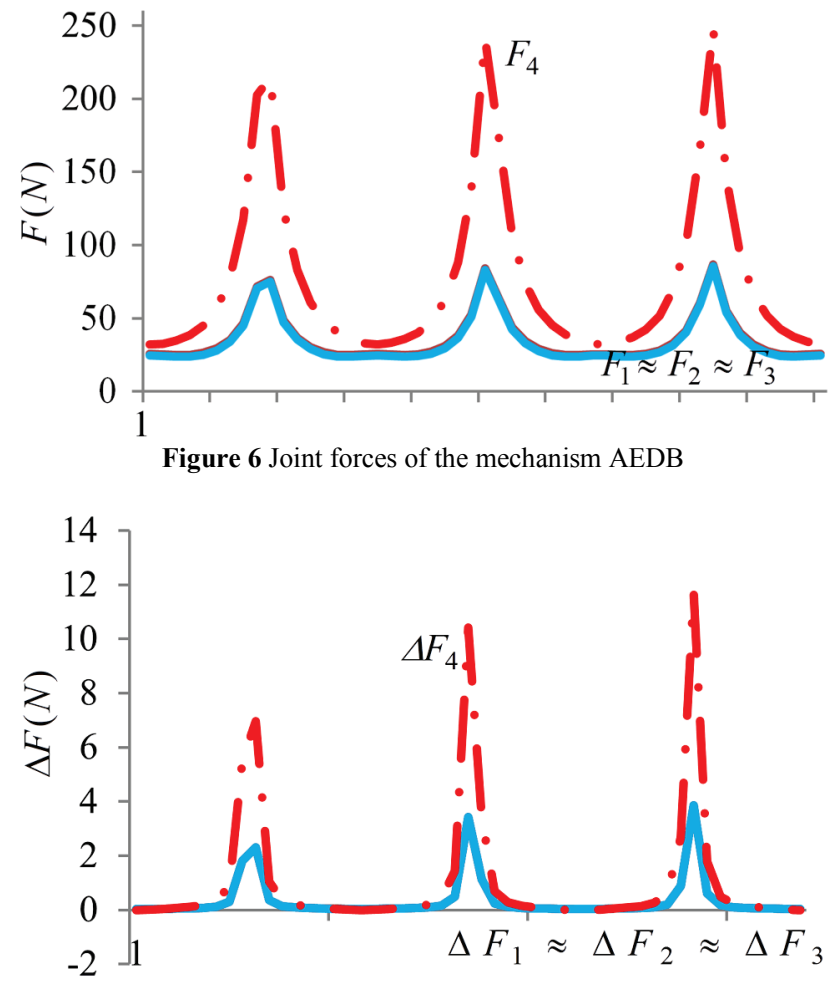

Figure 7 The effect of clearances on the joint forces of the mechanism AEDB obtained by the Taylor approximation

The joint forces during the movement are shown in Fig. 6, where: $F_{1} \approx F_{2} \approx F_{3}$ (full line - blue) and $F_{4}$ (dashed-dotted - red).

Fig. 7 shows the effect of clearances on joint reaction forces, obtained by the Taylor approximation, where: $\Delta F_{1} \approx \Delta F_{2} \approx \Delta F_{3}$ (full line - blue) and $\Delta F_{4}$ (dasheddotted - red).

\section{Conclusions}

By utilizing an adequate mathematical model of the mechanical system the effects of random parameters on forces in a kinematic chain can be estimated. In this paper a hydraulic support and a car wiper were considered. It was shown that the clearance in joints has some influence on the joint reaction forces. This influence varies as the kinematic chain operates. However, for the considered examples the magnitudes of these variations were rather minor except maybe at some position of the car wiper mechanism. So, one can say that for usual mechanisms with rather large security factors the influence of considered random parameters may probably be neglected. However, for highly loaded mechanisms the presented approach might provide valuable additional information on the actual loads emerging during operation.

\section{References}

[1] Rudall, B. H. Reports \& Surveys. // Robotica. 15, (1997), pp. 241-249.

[2] Yoshikawa, T. Manipulability of Robotic Mechanisms. // The International Journal of Robotic Research. 4, (1985), pp. 3-9.

[3] Conkur, E. S.; Buckingham, R. Clarifying the definition of redundancy as used in robotics. // Robotica. 15, (1997), pp. 583-586.

[4] Gamarra-Rosado, V. O.; Yuhara, E. A. O. Dynamic modeling and simulation of a flexible robotic manipulator. // Robotica. 17, (1999), pp. 523-528.

[5] Arora, J. S.; Wang, Q. Rewiew of formulations for structural and mechanical system optimization. // Structural and Multidisciplinary Optimization. 30, (2005), pp. 251272.

[6] Oblak, M.; Harl, B.; Butinar, B. Optimal design of hydraulic support. // Structural Optimization. 20, 1(2000), pp. 76-82.

[7] Dhande, S. G.; Chakraborty, J. Analysis and Synthesis of Mechanical Error in Linkages - A Stohastic Approach. // ASME Journal of mechanical design. (1973), pp. 672-676.

[8] Lee, S. J.; Gilmore, B. J. The determination of the probabilistic properties of velocities and accelerations in kinematic chains with uncertainty. // ASME Journal of mechanical design. (1989), pp. 225-232.

[9] Kegl, M.; Butinar, B.; Oblak, M. Optimization of mechanical systems: On strategy of non-linear first-order approximation. // Int. J. Numer. methods Eng. 33, (1991), pp. 223-234.

[10] Yoo, J.; Hajela, P. Immune network simulations in multicriterion design. // Structural Optimisation. 18, (1999), pp. 85-94.

[11] Harl, B.; Oblak, M.; Butinar, B. Minimization of joint reaction forces of kinematic chains by a multi-objective approach. // Struct. multidiscipl. optim. 27, 4(2004), pp. 243-249.

\section{Authors' addresses}

Boštjan Harl, doc. dr.

Nenad Gubeljak, prof. $d r$.

Marko Kegl, prof. dr.

University of Maribor, Facutly of Mech. Eng.

Smetanova 17, 2000 Maribor, Slovenia

E-mail: bostjan.harl@uni-mb.si 